\title{
Elephant seal dive behaviour is influenced by ocean temperature: implications for climate change impacts on an ocean predator
}

\author{
Trevor McIntyre ${ }^{1, *}$, Isabelle J. Ansorge ${ }^{2}$, Horst Bornemann ${ }^{3}$, Joachim Plötz ${ }^{3}$, \\ Cheryl A. Tosh ${ }^{1}$, Marthán N. Bester ${ }^{1}$ \\ ${ }^{1}$ Mammal Research Institute, Department of Zoology and Entomology, University of Pretoria, Private Bag X20, Hatfield 0028, \\ South Africa \\ ${ }^{2}$ Department of Oceanography, Marine Research Institute, University of Cape Town, Rondebosch 7701, South Africa \\ ${ }^{3}$ Alfred Wegener Institute for Polar and Marine Research, Postfach 120161, 27515 Bremerhaven, Germany
}

\begin{abstract}
The potential effects of ocean warming on marine predators are largely unknown, though the impact on the distribution of prey in vertical space may have far reaching impacts on diving predators such as southern elephant seals. We used data from satellite-tracked southern elephant seals from Marion Island to investigate the relationship between their dive characteristics (dive depths, dive durations and time-at-depth index values) and environmental variables (temperature at depth, depth of maximum temperature below $100 \mathrm{~m}$, frontal zone and bathymetry) as well as other demographic and behavioural variables (migration stage, age-class, track day and vertical diel strategy). While other variables, such as bathymetry and vertical diel strategy also influenced dive depth, our results consistently indicated a significant influence of temperature at depth on dive depths. This relationship was positive for all groups of animals, indicating that seals dived to deeper depths when foraging in warmer waters. Female seals adjusted their dive depths proportionally more than males in warmer water. Dive durations were also influenced by temperature at depth, though to a lesser extent. Results from time-at-depth indices showed that both male and female seals spent less time at targeted dive depths in warmer water, and were presumably less successful foragers when diving in warmer water. Continued warming of the Southern Ocean may result in the distribution of prey for southern elephant seals shifting either poleward and/or to increasing depths. Marion Island elephant seals are expected to adapt their ranging and diving behaviour accordingly, though such changes may result in greater physiological costs associated with foraging.
\end{abstract}

KEY WORDS: Climate change - Southern elephant seals · Foraging ecology · Marine mammals • Bio-logging $\cdot$ Marion Island

Resale or republication not permitted without written consent of the publisher

\section{INTRODUCTION}

The world's oceans are warming and this trend is likely to continue as climate impacts become more pronounced (Levitus et al. 2000, Solomon et al. 2009). The Southern Ocean in particular is warming. Recent studies have shown that, since the 1950s, the Antarc- tic Circumpolar Current (ACC) has strengthened and migrated southwards by 50 to $70 \mathrm{~km}$, resulting in an increase in global ocean temperatures in the upper $1000 \mathrm{~m}$ (Gille 2002). This warming has further been linked to changes in wind stress, which has shown a southward expansion of the Southern Hemisphere westerlies over a 30 yr period (Large \& Yeager 2004), 
thereby influencing the Southern Ocean eddy field and its contribution to the poleward heat flux (Meredith \& Hogg 2006). Indeed, hydrographic data collected north of the Prince Edward Islands for the period 1959 to 1999 indicate a positive trend in the southward migration of the Subantarctic Front (SAF) (Pakhomov \& Chown 2003, Ansorge et al. 2009). The most rapid warming appears to be concentrated along the Subantarctic Belt (Le Roux \& McGeoch 2008) and at the SAF (Gille 2002). Such changes in water temperature are causing complex changes in marine ecosystems across the world, notably changes in species' geographic distributions accompanied by simultaneous changes in vertical distribution (Perry et al. 2005, Dulvy et al. 2008, Nye et al. 2009). The effects of such climate changes on marine mammals may be direct (e.g. through loss of habitat from seaice breakup, Ferguson et al. 2005), or indirect (e.g. through changes in prey availability and distribution, susceptibility to diseases etc., Learmonth et al. 2006, Simmonds \& Isaac 2007).

The distribution of prey species in time and space influences the dive behaviour of marine mammals, especially pinnipeds (Hindell et al. 1991, Harcourt et al. 2002). Southern elephant seals Mirounga leonina are high trophic level predators in the Southern Ocean and have a circumpolar distribution (Le Boeuf \& Laws 1994). Links have previously been explored between population demographics of the species and climatic changes, suggesting that first year survival may be affected by changes in oceanographic conditions related to the El Niño Southern Oscillation (ENSO) (McMahon \& Burton 2005). The distribution and dive behaviour of elephant seals has also been related to oceanographic conditions. Some southern elephant seals from the Kerguelen Islands tend to focus their forage efforts on zones with specific temperature signatures (Bailleul et al. 2007). Female southern elephant seals from Macquarie Island apparently do not alter their dive behaviour in response to changes in thermal structure, though differences in dive behaviour are evident as seals move between different water bodies (Field et al. 2001). Broaderscale assessments have described associations of forage locations with inter-frontal zones (Jonker \& Bester 1998, van den Hoff et al. 2002), continental shelves and areas close to the Antarctic ice edge (Bornemann et al. 2000, Biuw et al. 2007, Tosh et al. 2009), as well as mesoscale features such as eddies (Bailleul et al. 2010b, Dragon et al. 2010). The use of oceanographic data collected in situ by animal-borne devices may further enhance our understanding of diving responses to oceanographic conditions.
Marion Island $\left(46^{\circ} 54^{\prime} \mathrm{S}, 37^{\circ} 45^{\prime} \mathrm{E}\right)$ is one of 2 islands that together form the Prince Edward Islands (PEI). Southern elephant seals from Marion Island forage over a wide area of the Southern Ocean that stretches from the Antarctic shelf in the south to areas north of the SAF in the north (Jonker \& Bester 1998, Tosh 2010). Animals typically return to the island twice a year, for giving birth, nursing pups and mating during the austral spring, and again for moulting later in the austral summer (Le Boeuf \& Laws 1994). This results in 2 forage migrations per year, a postmoult (PM) trip lasting up to $9 \mathrm{mo}$, and a shorter postbreeding (PB) trip of approximately 3 mo. The Marion Island population is one of the northernmost breeding colonies and its animals are extreme divers that spend more than $65 \%$ of their lives at sea in depths deeper than $100 \mathrm{~m}$ (McIntyre et al. 2010a). Although short-term variability (i.e. changes in eddy intensity or frequency) cannot be completely discounted, there is strong evidence that sea temperatures close to the islands continue to rise (Mélice et al. 2003) and top predators from PEI are considered likely to be influenced significantly by such warming. Here we used temperature data recorded in situ to model the influences of temperature at depth and other variables on the dive behaviour of Marion Island elephant seals.

\section{MATERIALS AND METHODS}

\section{Deployments}

We deployed 59 satellite-relay data loggers (SRDLs) (Sea Mammal Research Institute, University of St. Andrews, Scotland) between 2004 and 2008 on southern elephant seals hauled out at Marion Island $\left(46^{\circ} 54^{\prime} \mathrm{S} ; 37^{\circ} 45^{\prime} \mathrm{E}\right)$. Animals were immobilised following the method of Bester (1988), and SRDLs were glued to the dorsal, cranial pelage as detailed by McIntyre et al. (2010a). Two SRDL models were used, namely the Series 9000 SRDL and CTD-SRDL. Series 9000 SRDLs recorded and transmitted, via Service Argos (Argos 1996), abstracted dive profiles and temperature profiles with an accuracy better than $0.01^{\circ} \mathrm{C}$ (Boehme et al. 2009). CTD-SRDLs were additionally fitted with a conductivity sensor (Valeport, Boehme et al. 2009). Location estimates for animals were obtained via Service Argos and interpolated locations attributed to individual dive profiles by the manufacturers (Sea Mammal Research Institute). All dive, temperature and conductivity data, as well as the related meta-information, are available via the PANGEA information system (http://pangaea.de). 


\section{Dives/temperature profiles}

We calculated local times and local times of sunset and sunrise for each transmitted dive profile, using the 'maptools' package in the R environment (LewinKoh \& Bivand 2008, R Development Core Team 2008). Each dive was accordingly labelled as having taken place either during daytime, night-time, or during sunset/sunrise (sunset/sunrise was defined as the period falling within $30 \mathrm{~min}$ before and after the calculated time).

Transmitted dive and temperature profiles do not necessarily correspond temporally or spatially with one another, since information is compressed and stored temporarily in a buffer on board the SRDLs prior to transmission (Boehme et al. 2009). We therefore calculated daily averaged values of various dive parameters and temperature profiles in order to make them comparable and further to eliminate potential biases due to variable uplink rates. To account for expected differences in dive characteristics between different oceanographic zones, we assigned each dive day to a frontal zone based on the averaged location of uplinks received for the particular day and estimated frontal positions following Belkin \& Gordon (1996). Accordingly daily locations were classified as either occurring north of the SAF, between the SAF and the Antarctic Polar Front (APF), or south of the APF.

Elephant seals from Marion Island have been documented to display positive, as well as negative diel vertical migration (i.e. positive = diving deeper during the day compared to night-time; negative = diving deeper at night compared to daytime) patterns in dive depths whilst foraging pelagically (McIntyre et al. 2011). A diel vertical strategy (DVS) was therefore assigned to each dive day. Accordingly, seals were considered to make use of a positive DVS if the difference between mean dive depths during the day $(-\mathrm{SE})$ and mean dive depths at night $(+\mathrm{SE})$ exceeded $25 \mathrm{~m}$. If this difference was smaller than $-25 \mathrm{~m}$ (i.e. the seal dived substantially deeper at night, compared to during the day) a negative DVS was attributed, and if this difference was between $-25 \mathrm{~m}$ and $25 \mathrm{~m}$, the seal was considered to make use of a neutral DVS. A cut-off value of $25 \mathrm{~m}$ was chosen as representing a value of approximately $5 \%$ of the mean dive depths of southern elephant seals from this population (McIntyre et al. 2010a).

A time-at-depth index (TAD) was calculated following Fedak et al. (2001), providing a depth- and duration-independent index, indicating the relative depth where an animal centred its activity. Accord- ingly, values close to 1 are indicative of an animal maximising the amount of time close to the maximum depth of a dive. Values approaching 0.5 are indicative of an animal spending more or less equal amounts of time at all recorded dive depths and values closer to 0 are obtained when an animal spends most of the dive time close to the sea surface and only makes a short excursion to the maximum depth recorded. Since elephant seal dives can be classified into various 'types', based on their time-depth characteristics (Hindell et al. 1991, Jonker \& Bester 1994, Biuw et al. 2007), we restricted the daily averaged TAD values to specific dive types thought to have a foraging purpose. We used a method that employs Breiman's random forest (RF) algorithm (Breiman 2001) to classify each dive into 1 of 6 recognized types, namely square (SQ), root (R), drift (DR), U-shaped (U), V-shaped (V) and wiggle (W) dives (see Photopoulos 2007, McIntyre et al. 2011). A total of 18 derived variables were used for the RF classification. The RF tree-building method was employed using the 'randomForest' package in $\mathrm{R}$ (Liaw \& Wiener 2002). We restricted the calculations of averaged TAD values to $\mathrm{U}$ - and $\mathrm{W}$-shaped dives. SQ dives were not included in our analyses, since they made up a very small proportion $(<1 \%)$ of dives classified. We further calculated the daily ratio of $\mathrm{U}$ - and W-shaped dives (combined) as a proxy for frequency of forage-type diving. A summary of derived dive and temperature parameters is provided in Table 1.

Temperature profiles were inspected visually in Ocean Data View (Schlitzer 2002) and unrealistic or incomplete profiles removed. Profiles were considered unrealistic when they contained extreme outlying values $\left(<-3^{\circ} \mathrm{C}\right.$ or $\left.>15^{\circ} \mathrm{C}\right)$ and/or values within the same profile that differed by more than $40 \%$ from preceding and subsequent values. Most of the temperature profiles obtained in the Southern Ocean are characterised by a maximum temperature $\left(T_{\max }\right)$ layer occurring relatively close to the surface (Pollard et al. 2002). Since southern elephant seals spend more than $80 \%$ of their time at sea at depths deeper than $100 \mathrm{~m}$ (McIntyre et al. 2010a), we calculated the maximum temperature recorded at depths exceeding $100 \mathrm{~m}\left(T_{\max } 100\right)$ for each of the recorded temperature profiles. These values were then averaged to obtain daily averaged $T_{\max } 100$ values, as well as mean depth values where the $T_{\max } 100$ was recorded ( $T_{\max }$ 100.depth). Temperature characteristics at depth were assumed not to differ significantly between day and night.

Dive durations recorded by the female elephant seals in our sample generally increased initially dur- 
Table 1. Descriptions of parameters used in mixed-effects models

\begin{tabular}{|c|c|c|}
\hline Parameter & Description & Classification \\
\hline \multicolumn{3}{|l|}{ Fixed variables } \\
\hline TDAY & Track day & Day number since start of track \\
\hline AGE CLASS & Females & $\begin{array}{l}\text { Subadults (younger than } 3 \text { yr) } \\
\text { Adults (older than } 3 \text { yr) }\end{array}$ \\
\hline & Males & $\begin{array}{l}\text { Subadults (younger than } 6 \text { yr) } \\
\text { Adults (older than } 6 \text { yr) }\end{array}$ \\
\hline MIGRATION & Migration stage & $\begin{array}{l}\text { Post-moult (i.e. approx. Feb to Oct) } \\
\text { Post-breeding (i.e. approx. Nov to Dec/Jan) }\end{array}$ \\
\hline FZ & $\begin{array}{l}\text { Frontal zone of daily } \\
\text { averaged locations }\end{array}$ & $\begin{array}{l}\text { North of the SAF } \\
\text { Between SAF and APF } \\
\text { South of the APF }\end{array}$ \\
\hline ВОТТОМ & Bottom depth & $\begin{array}{l}\text { Interpolated depth estimates obtained from the Gebco Digital } \\
\text { Atlas (IOC et al. 2003) }\end{array}$ \\
\hline DVS & Diel vertical strategy & $\begin{array}{l}\text { Positive (difference between day- and night-time dive depths } \\
\text { greater than } 25 \mathrm{~m} \text { ) } \\
\text { Negative (difference between day- and night-time dive depths } \\
\text { smaller than }-25 \mathrm{~m} \text { ) } \\
\text { Neutral (difference between day- and night-time dive depths } \\
\text { between - } 25 \text { and } 25 \mathrm{~m} \text { ) }\end{array}$ \\
\hline$T_{\max } 100$ & Maximum temperature & $\begin{array}{l}\text { Mean maximum temperature recorded at depths deeper than } \\
100 \mathrm{~m}\left({ }^{\circ} \mathrm{C}\right)\end{array}$ \\
\hline$T_{\max }$ 100.depth & Depth of maximum temperature & Mean depth at which $T_{\max } 100$ was recorded (m) \\
\hline \multicolumn{3}{|c|}{ Response variables } \\
\hline TAD & Time-at-depth index & $\begin{array}{l}\text { Mean TAD value of U- and W-shaped dives, calculated follow- } \\
\text { ing Fedak et al. (2001) }\end{array}$ \\
\hline $\mathrm{DDEP}_{\text {day }}$ & Dive depth daytime & Mean dive depths obtained during daytime (m) \\
\hline $\mathrm{DDEP}_{\text {night }}$ & Dive depth night-time & Mean dive depths obtained during night-time (m) \\
\hline DDUR $_{\text {day }}$ & Dive duration daytime & Mean dive durations during daytime (s) \\
\hline DDUR $_{\text {night }}$ & Dive duration night-time & Mean dive durations during night-time (s) \\
\hline
\end{tabular}

ing migrations, and was followed by a decrease from approximately $150 \mathrm{~d}$ into the migration, prior to returning to Marion Island. We therefore restricted the females' dive duration data used in the linear mixed models (see below) to data obtained within the first $150 \mathrm{~d}$ of individual migrations to satisfy model assumptions. Mean dive depths recorded for male seals were log-transformed to account for very deep dives recorded by one seal in the sample (details reported in McIntyre et al. 2010a).

\section{Statistical analyses}

We used linear mixed effects models to model the influences of age class, migration stage (PM or PB), track day (TDAY), frontal zone of dive location (FZ: north of $\mathrm{SAF}_{\text {; }}$ between $\mathrm{SAF}$ and $\mathrm{APF}$; or south of APF), bathymetry (seafloor depth), DVS, $T_{\max } 100$ and $T_{\max }$ 100.depth on various dive parameters (dive depth, dive duration and TAD). Dive depths and dive durations were separated by day-stage (night and day) to account for expected differences in values due to diel vertical migration (Jonker \& Bester 1994, Bennett et al. 2001). Since southern elephant seals are known to segregate sexually in depth use patterns (McIntyre et al. 2010b), we analysed data separately for males and females. Mixed models allow for the unbalanced design resulting from our sample, as well as the explicit modelling of temporal autocorrelation inherent to our data (Pinheiro \& Bates 2004, Bolker et al. 2009). They further allow for variance differences between random variables (individual animals in our sample). Maximum likelihood estimation was employed following Bolker et al. (2009).

We employed second order Akaike's information criterion $\left(\mathrm{AIC}_{\mathrm{c}}\right)$ statistics for small sample sizes (Burnham \& Anderson 2002) to govern model selection. Best models were chosen using backward selection starting with full models that included all fixed effects. Various plot types were used to assess model fits (Pinheiro \& Bates 2004, Crawley 2007). Hypothe- 
sis tests ( $F$-tests) were carried out on the final models to distinguish significance of the various fixed effects (Bolker 2008, Bolker et al. 2009). We also carried out variance components analyses on the final models to estimate the variation explained by random effects (Bunnefeld et al. 2009).

All statistical analyses were carried out in $\mathrm{R}$ version 2.7.1 (R Development Core Team 2008), with significance set at $p \leq 0.05$. Unless otherwise stated, summary statistics are reported as means $\pm \mathrm{SD}$.

\section{ARGO data}

The ARGO float programme provides an extensive year round dataset of the world's oceans, and in particular provides information in parts of the ocean difficult to map such as the Southern Ocean and the south Indian Ocean (Roemmich \& Owens 2000, Roemmich et al. 2004). ARGO floats provide high quality temperature and salinity profiles for the top $2000 \mathrm{~m}$ of the ocean, plus mid-depth drift trajectories, every $10 \mathrm{~d}$. ARGO's objective is to build and maintain a 3000 float array (Wilson 2000). For this study, quality controlled temperature profiles from ARGO float data were obtained from the Global Marine ARGO atlas (Roemmich \& Gilson 2009) for the period March 2004 to 2010.

\section{RESULTS}

Early tag failure (within $30 \mathrm{~d}$ from deployment) and/or failure of temperature probes on 15 satellite tags resulted in data being retained from 44 deployments. Eight animals were instrumented multiple times and 2 instruments continued functioning over 2 subsequent migrations (PM and PB). This resulted in data being retained for analyses from 46 tracks, resulting from 44 deployments made on 33 individual animals. Females accounted for $27(\mathrm{PM}=19 ; \mathrm{PB}=8)$ of the tracks, while males accounted for 19 (adult males $\mathrm{PM}=5$; adult males $\mathrm{PB}=4$; subadult males $=$ $10)$ of the tracks analysed here. We did not distinguish between age classes for female southern elephant seals, since our sample did not allow for the adequate quantification of subadult female $(n=2)$ dive characteristics. Summary dive statistics for these tracks are reported in Table 2.

Most of the animals in our sample travelled in westerly and south-westerly directions away from Marion Island during their foraging migrations (Fig. 1). One subadult male travelled in an easterly direction, however, toward Îles Crozet. More detailed analyses of dive behaviours recorded by southern elephant seals in this sample are reported elsewhere (McIntyre et al. 2011).

Full models for dive parameters included age class (restricted to models for male dive parameters), FZ, migration, DVS, bottom depth, $T_{\max } 100$ and $T_{\max }$ 100.depth as fixed effects. Individual was included as random effect in all models. Autoregressive moving average autocorrelation functions were incorporated in all models with best fits to account for the inherent temporal autocorrelation evident in the data (Pinheiro \& Bates 2004) (Table 3).

\section{Dive depths}

Model results indicated that dive depths recorded during both day- and night-time for both sexes were

Table 2. Summary values (mean $\pm \mathrm{SD}$ ) of dive parameters recorded for animals in this study. $\mathrm{FOR}_{\text {day }}$ and FOR $\mathrm{R}_{\text {night }}$ are the mean $( \pm \mathrm{SD})$ proportions of dives that were classified as 'forage-type' dives (i.e. had time-depth profiles classified as U- or W-shaped)

\begin{tabular}{|c|c|c|c|c|c|c|}
\hline & \multicolumn{3}{|c|}{$\longrightarrow$ Males $\left(\mathrm{n}_{\text {individuals }}=15\right)$} & \multicolumn{3}{|c|}{ Females $\left(\mathrm{n}_{\text {individuals }}=18\right)$} \\
\hline & \multirow{2}{*}{\multicolumn{2}{|c|}{ 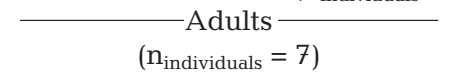 }} & \multirow{3}{*}{$\begin{array}{c}\text { Subadults } \\
\left(\mathrm{n}_{\text {individuals }}=9\right) \\
\left(\mathrm{n}_{\text {tracks }}=10\right)\end{array}$} & $\longrightarrow \mathrm{Adu}$ & lts & Subadults \\
\hline & & & & $\left(\mathrm{n}_{\text {individuc }}\right.$ & ls $=17)$ & $\left(\mathrm{n}_{\text {individuals }}=2\right)$ \\
\hline & $\mathrm{PM}\left(\mathrm{n}_{\text {tracks }}=5\right)$ & PB $\left(\mathrm{n}_{\text {tracks }}=4\right)$ & & $\mathrm{PM}\left(\mathrm{n}_{\text {tracks }}=17\right)$ & $\mathrm{PB}\left(\mathrm{n}_{\text {tracks }}=8\right)$ & $\left(\mathrm{n}_{\text {tracks }}=2\right)$ \\
\hline nDIVES $S_{\text {day }}$ & 3139 & 4326 & 14417 & 30808 & 7594 & 1389 \\
\hline nDIVES night & 5568 & 2189 & 21698 & 49988 & 5666 & 3134 \\
\hline $\operatorname{DDEP}_{\text {day }}(\mathrm{m})$ & $767.3 \pm 327.3$ & $472.8 \pm 101.4$ & $669.5 \pm 144.7$ & $582.6 \pm 120.7$ & $532 \pm 97.1$ & $621.2 \pm 83.1$ \\
\hline $\mathrm{DDEP}_{\text {night }}(\mathrm{m})$ & $560.5 \pm 309.1$ & $374.9 \pm 87.9$ & $469 \pm 150.6$ & $398.6 \pm 96.2$ & $363.9 \pm 113$ & $432.3 \pm 64$ \\
\hline $\mathrm{DDUR}_{\text {day }}(\mathrm{min})$ & $38.3 \pm 10.4$ & $29.2 \pm 4.8$ & $36.5 \pm 11$ & $34.3 \pm 10.1$ & $24 \pm 4.5$ & $34.9 \pm 4.5$ \\
\hline DDUR $_{\text {night }}(\mathrm{min})$ & $30.7 \pm 8$ & $24.4 \pm 5$ & $26.7 \pm 9.1$ & $25.4 \pm 7.3$ & $16.3 \pm 3$ & $24.5 \pm 3.6$ \\
\hline $\mathrm{FOR}_{\text {day }}$ & $0.91 \pm 0.19$ & $0.97 \pm 0.04$ & $0.94 \pm 0.1$ & $0.96 \pm 0.07$ & $0.96 \pm 0.07$ & $0.94 \pm 0.09$ \\
\hline $\mathrm{FOR}_{\text {night }}$ & $0.95 \pm 0.09$ & $0.96 \pm 0.09$ & $0.93 \pm 0.1$ & $0.96 \pm 0.07$ & $0.96 \pm 0.07$ & $0.93 \pm 0.07$ \\
\hline TAD & $0.64 \pm 0.1$ & $0.74 \pm 0.08$ & $0.63 \pm 0.09$ & $0.69 \pm 0.13$ & $0.64 \pm 0.2$ & $0.57 \pm 0.08$ \\
\hline
\end{tabular}




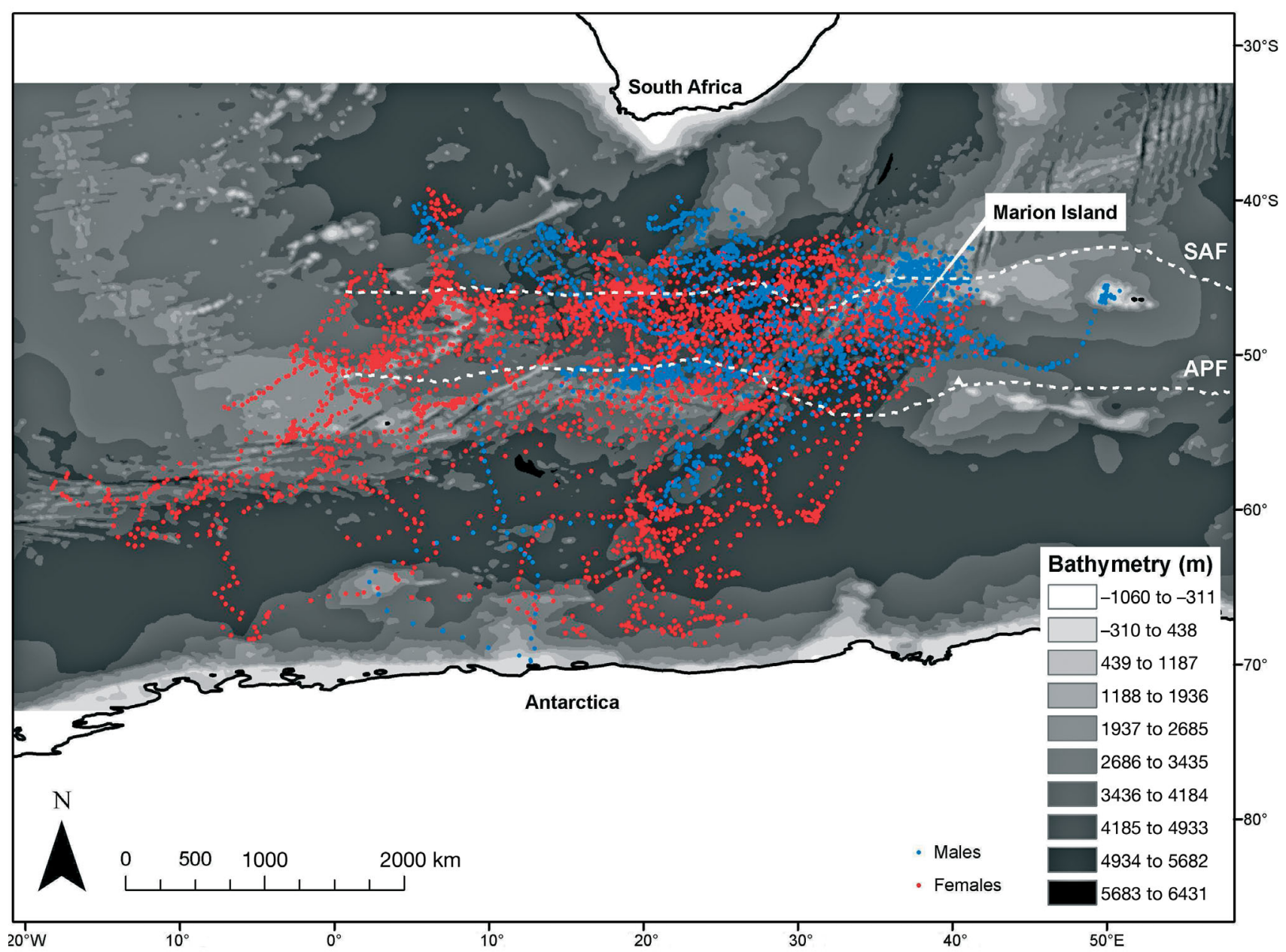

Fig. 1. Daily averaged dive locations for the seal tracks used in this study. Approximate positions of the Subantarctic Front (SAF) and Antarctic Polar Front (APF) are indicated, following Belkin \& Gordon (1996)

Table 3. Summary of models with best fits. $\Delta \mathrm{AIC}_{\mathrm{C}}=$ the difference in $\mathrm{AIC}_{\mathrm{c}}$ between the final model and the initial full model, containing all parameters; $\mathrm{RE}=$ random effect. Correlation structures for all final models were autoregressive moving average (ARMA) functions

\begin{tabular}{|c|c|c|c|c|}
\hline Parameter & Model & $\Delta \mathrm{AIC}_{\mathrm{c}}$ & Correlation structure & $\mathrm{RE}$ \\
\hline \multicolumn{5}{|l|}{ MALES } \\
\hline $\mathrm{DDEP}_{\text {day }}$ & $\log \left(\mathrm{DDEP}_{\text {day }}\right) \sim$ AGE.CLASS + BOTTOM + DVS + FZ + $T_{\max } 100$ & 715.21 & ARMA $(p=2, q=2)$ & 44.17 \\
\hline $\mathrm{DDEP}_{\text {night }}$ & $\begin{array}{l}\log \left(\text { DDEP }_{\text {night }}\right) \sim \text { AGE.CLASS + BOTTOM + DVS + } \\
T_{\max } 100+T_{\max } 100 . \text { depth }\end{array}$ & 623.03 & ARMA $(p=2, q=2)$ & 11.8 \\
\hline DDUR $_{\text {day }}$ & $\mathrm{DDUR}_{\text {day }} \sim \mathrm{TDAY}+\mathrm{AGE} \cdot \mathrm{CLASS}+\mathrm{DVS}+T_{\max } 100$ & 1055.58 & ARMA $(p=3, q=3)$ & 16.72 \\
\hline DDUR $_{\text {night }}$ & DDUR $_{\text {night }} \sim$ TDAY + AGE.CLASS + MIGRATION + DVS & 1172.69 & ARMA $(p=2, q=2)$ & 37.87 \\
\hline TAD & TAD MIGRATION + DVS + $T_{\max } 100$ & 332.59 & ARMA $(p=2, q=2)$ & 20.73 \\
\hline \multicolumn{5}{|l|}{ FEMALES } \\
\hline $\mathrm{DDEP}_{\text {day }}$ & $\mathrm{DDEP}_{\mathrm{day}} \sim \mathrm{TDAY}+\mathrm{BOTTOM}+\mathrm{DVS}+\mathrm{FZ}+T_{\max } 100$ & 1195.32 & ARMA $(p=2, q=2)$ & $<0.01$ \\
\hline $\mathrm{DDEP}_{\text {night }}$ & $\begin{array}{l}\text { DDEP } \text { night } \sim \text { TDAY + BOTTOM + DVS + FZ + } T_{\max } 100+ \\
T_{\max } 100 . \text { depth }\end{array}$ & 1366.57 & ARMA $(p=3, q=3)$ & 4.37 \\
\hline DDUR $_{\text {day }}$ & $\mathrm{DDUR}_{\mathrm{day}} \sim \mathrm{TDAY}+\mathrm{MIGRATION}+\mathrm{DVS}+T_{\max } 100$ & 2579.27 & ARMA $(p=1, q=1)$ & $<0.01$ \\
\hline DDUR $_{\text {night }}$ & $\mathrm{DDUR}_{\text {night }} \sim \mathrm{TDAY}+\mathrm{DVS}+T_{\max } 100$ & 2394.83 & ARMA $(p=2, q=2)$ & $<0.01$ \\
\hline TAD & $\mathrm{TAD} \sim \mathrm{DVS}+T_{\max } 100$ & 490.26 & ARMA $(p=2, q=2)$ & $<0.01$ \\
\hline
\end{tabular}


significantly influenced by DVS (Tables $3 \& 4$ ). Dive depths recorded during day- and night-times for both males and females were also significantly influenced by $T_{\max } 100$ (Tables 3 \& 4). A positive relationship was evident in all cases, with dives being deeper in warmer water temperatures (for example Fig. 2). Model coefficients indicated that this relationship was stronger for females $($ daytime $=9.24 ;$ night-time $=10.14)$ than for males (daytime $=0.03$; nighttime $=0.03$ ). Mean night-time dive depths undertaken by both sexes were also significantly influenced by $T_{\max }$ 100.depth, dives becoming shallower when the $T_{\max } 100$.depth was deeper (though maximum night-time dive depths were deeper than $T_{\max } 100 . d e p t h$ in $96 \%$ of the dives recorded).

Female day- and night-time dive depths were further significantly influenced by TDAY and bottom depth. Both these variables exhibited a positive relationship with dive depth, with recorded dives being deeper in areas with deeper bathymetry (higher bottom depth values), and also becoming deeper as tracks become longer. Male night-time dive depths were also significantly influenced by bottom depth, though model coefficients indicated this influence to be small $(<0.00)$. Male daytime dive depths were additionally influenced by migration stage, with deeper dives recorded during PM migrations $(687.6 \pm 194.8 \mathrm{~m})$ than during $\mathrm{PB}$ migrations $(473.1 \pm 101.5 \mathrm{~m})$.

The random effects (track) explained between 0 and $4.4 \%$ of the variance in female dive depths, but between 11.8 and $44.2 \%$ of the variance in male dive depths (Table 3 ).

\section{Dive durations}

Excluding night-time dives undertaken by male seals, dive durations were significantly influenced by
Table 4. F-test results indicating significant fixed effects on final models. Bold: significant $(\mathrm{p} \leq 0.05)$. Parameter abbreviations are as for Table 1

\begin{tabular}{|c|c|c|c|c|c|}
\hline Parameter & Fixed effect & Coefficient & $F$ & $\mathrm{df}$ & $\mathrm{p}$ \\
\hline \multicolumn{6}{|l|}{ MALES } \\
\hline \multirow[t]{6}{*}{$\mathrm{DDEP}_{\text {day }}$} & (Intercept) & 6.168 & 12489.83 & 1,1946 & $<0.0001$ \\
\hline & AGE.CLASS & -0.137 & 6.41 & 1,1946 & 0.011 \\
\hline & ВОтТОМ & 0.000 & 3.07 & 1,1946 & 0.080 \\
\hline & DVS & 0.123 & 593.25 & 1,1946 & $<0.0001$ \\
\hline & $\mathrm{FZ}$ & 0.032 & 0.87 & 1,1946 & 0.350 \\
\hline & $T_{\max } 100$ & 0.032 & 55.72 & 1,1946 & $<0.0001$ \\
\hline \multirow[t]{6}{*}{$\mathrm{DDEP}_{\text {night }}$} & (Intercept) & 6.046 & 11846.10 & 1,1946 & $<0.0001$ \\
\hline & AGE.CLASS & -0.093 & 1.63 & 1,1946 & 0.202 \\
\hline & ВОТТОМ & 0.000 & 28.97 & 1,1946 & $<0.0001$ \\
\hline & DVS & -0.151 & 475.51 & 1,1946 & $<0.0001$ \\
\hline & $T_{\max } 100$ & 0.034 & 29.87 & 1,1946 & $<0.0001$ \\
\hline & $T_{\max }$ 100.depth & 0.000 & 19.95 & 1,1946 & $<0.0001$ \\
\hline \multirow[t]{5}{*}{ DDUR $_{\text {day }}$} & (Intercept) & 1787.539 & 432.06 & 1,1947 & $<0.0001$ \\
\hline & TDAY & 2.208 & 18.12 & 1,1947 & $<0.0001$ \\
\hline & AGE.CLASS & -271.850 & 4.43 & 1,1947 & 0.036 \\
\hline & DVS & 138.965 & 152.73 & 1,1947 & $<0.0001$ \\
\hline & $T_{\max } 100$ & 36.831 & 17.55 & 1,1947 & $<0.0001$ \\
\hline \multirow[t]{5}{*}{ DDUR $_{\text {night }}$} & (Intercept) & 2434.502 & 201.00 & 1,1947 & $<0.0001$ \\
\hline & TDAY & 1.396 & 7.16 & 1,1947 & 0.008 \\
\hline & AGE.CLASS & -399.761 & 7.29 & 1,1947 & 0.007 \\
\hline & MIGRATION & -383.737 & 6.22 & 1,1947 & 0.013 \\
\hline & DVS & -96.071 & 127.96 & 1,1947 & $<0.0001$ \\
\hline \multirow[t]{4}{*}{ TAD } & (Intercept) & 0.736 & 1656.53 & 1,1580 & $<0.0001$ \\
\hline & MIGRATION & -0.113 & 19.65 & 1,1580 & $<0.0001$ \\
\hline & DVS & 0.006 & 6.28 & 1,1580 & 0.012 \\
\hline & $T_{\max } 100$ & -0.003 & 4.35 & 1,1580 & 0.037 \\
\hline \multicolumn{6}{|l|}{ FEMALES } \\
\hline \multirow[t]{6}{*}{$\mathrm{DDEP}_{\text {day }}$} & (Intercept) & 302.608 & 6171.13 & 1,3286 & $<0.0001$ \\
\hline & TDAY & 0.470 & 54.24 & 1,3286 & $<0.0001$ \\
\hline & ВОТТОМ & 0.012 & 46.27 & 1,3286 & $<0.0001$ \\
\hline & DVS & 75.880 & 1329.41 & 1,3286 & $<0.0001$ \\
\hline & $\mathrm{FZ}$ & 7.956 & 0.71 & 1,3286 & 0.401 \\
\hline & $T_{\max } 100$ & 9.241 & 40.74 & 1,3286 & $<0.0001$ \\
\hline \multirow[t]{7}{*}{ DDEP $_{\text {night }}$} & (Intercept) & 342.065 & 2090.03 & 1,3285 & $<0.0001$ \\
\hline & TDAY & 0.127 & 5.76 & 1,3285 & 0.016 \\
\hline & ВОТТОМ & 0.008 & 9.78 & 1,3285 & 0.002 \\
\hline & DVS & -35.552 & 386.32 & 1,3285 & $<0.0001$ \\
\hline & $\mathrm{FZ}$ & 5.201 & 1.40 & 1,3285 & 0.236 \\
\hline & $T_{\max } 100$ & 10.142 & 42.93 & 1,3285 & $<0.0001$ \\
\hline & $T_{\max }$ 100.depth & 0.066 & 18.80 & 1,3285 & $<0.0001$ \\
\hline \multirow[t]{5}{*}{ DDUR $_{\text {day }}$} & (Intercept) & 1399.331 & 747.68 & 1,3287 & $<0.0001$ \\
\hline & TDAY & 3.332 & 74.37 & 1,3287 & $<0.0001$ \\
\hline & MIGRATION & -142.708 & 2.75 & 1,3287 & 0.097 \\
\hline & DVS & 160.478 & 341.45 & 1,3287 & $<0.0001$ \\
\hline & $T_{\max } 100$ & 12.975 & 4.73 & 1,3287 & 0.030 \\
\hline \multirow[t]{4}{*}{ DDUR $_{\text {night }}$} & (Intercept) & 1384.860 & 1055.44 & 1,3288 & $<0.0001$ \\
\hline & TDAY & 2.727 & 79.05 & 1,3288 & $<0.0001$ \\
\hline & DVS & -61.133 & 90.93 & 1,3288 & $<0.0001$ \\
\hline & $T_{\max } 100$ & -24.698 & 27.52 & 1,3288 & $<0.0001$ \\
\hline \multirow[t]{3}{*}{ TAD } & (Intercept) & 0.702 & 2641.65 & 1,2091 & $<0.0001$ \\
\hline & DVS & 0.011 & 7.50 & 1,2091 & 0.006 \\
\hline & $T_{\max } 100$ & -0.010 & 27.87 & 1,2091 & $<0.0001$ \\
\hline
\end{tabular}




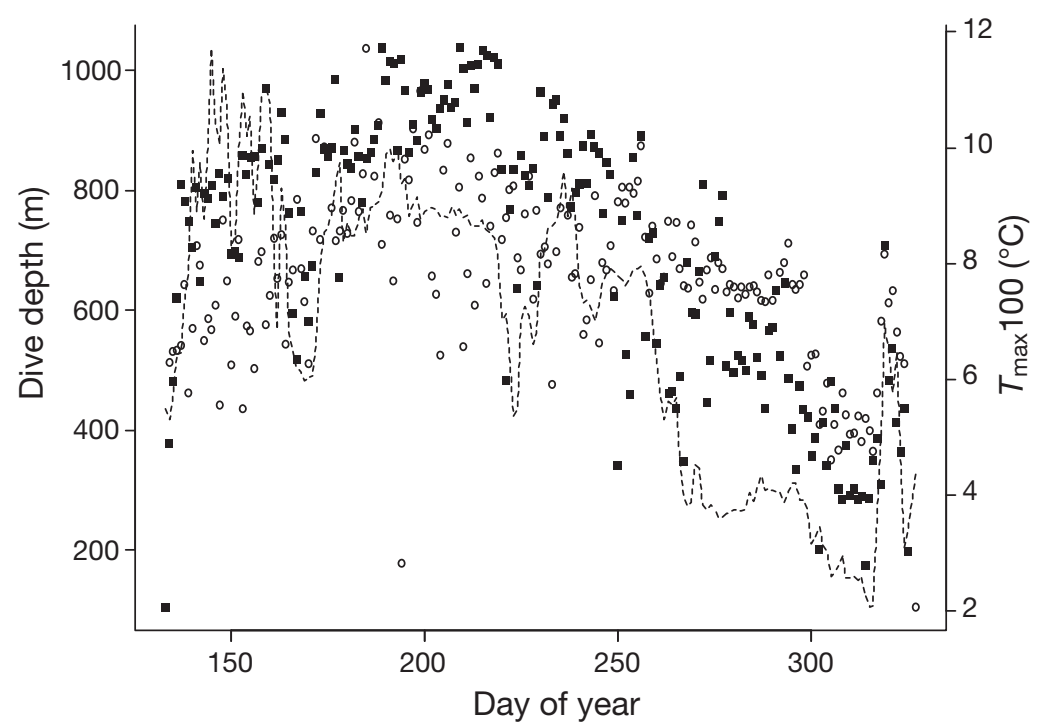

Fig. 2. Mirounga leonina. Example plot indicating the relationship in mean daily dive depths $(0=$ daytime; $=$ night-time $)$ and $T_{\max } 100(---)$ recorded for individual OO405 (subadult male) longer when animals displayed positive DVS (males: $36.5 \pm 10.1 \mathrm{~min}$; females: $33.6 \pm 9.4 \mathrm{~min})$ than when they displayed neutral (males: $34.8 \pm 12 \mathrm{~min}$; females: $32 \pm 10.9 \mathrm{~min}$ ) or negative (males: $35.2 \pm 12 \mathrm{~min}_{\text {; }}$ females: $28.5 \pm$ 11.8 min) DVS. Night-time dive durations were longer when animals displayed negative DVS (males: $32.8 \pm$ $9.1 \mathrm{~min}$; females: $27.1 \pm 8.6 \mathrm{~min}$ ) when compared to night-time dives while animals displayed neutral (males: $26.7 \pm 8.4 \mathrm{~min}$; females: $24.8 \pm 7.6 \mathrm{~min})$ or positive (males: $25.6 \pm 8 \mathrm{~min}$; females: $23.7 \pm 7.1 \mathrm{~min}$ ) DVS.

The random effects (track) explained less than $0.01 \%$ of the variance in female dive durations, and between $16.7 \%$ and $37.9 \%$ of the variance in male dive durations (Table 3).

\section{TAD}

$T_{\max } 100$ (Tables $3 \& 4$ ). This relationship was positive for all daytime dives, resulting in longer dives being undertaken when $T_{\max } 100$ increased. However, a negative relationship was evident for night-time dives undertaken by seals and dives were shorter when $T_{\max } 100$ increased. Model coefficients indicated that these relationships were slightly stronger for males, than for females (Table 4).

Male night-time dive durations were further influenced by migration stage and age class. PM dives $(27.5 \pm 9 \mathrm{~min})$ were longer than $\mathrm{PB}$ dives $(24.4 \pm 5 \mathrm{~min})$, and dives performed by adult males were longer on average than subadult males (adults: $28.4 \pm 7.7 \mathrm{~min}$; subadults: $26.7 \pm 9 \mathrm{~min}$ ). Female night-time dive durations also differed between migration stages (PM: $25.3 \pm 7.1 \mathrm{~min}$; PB: $16.3 \pm 3 \mathrm{~min}$ ). While migration stage was included in the most parsimonious model for female night-time dive durations, F-test results indicated this effect not to be statistically significant (Table 4).

Dive durations recorded for day- and night-time dives by both sexes were significantly influenced by DVS and TDAY (Tables 3 \& 4). Dive durations displayed a positive relationship with TDAY, becoming longer as TDAY increased. DVS influenced dive durations in a similar manner to dive depths. Daytime dive durations were

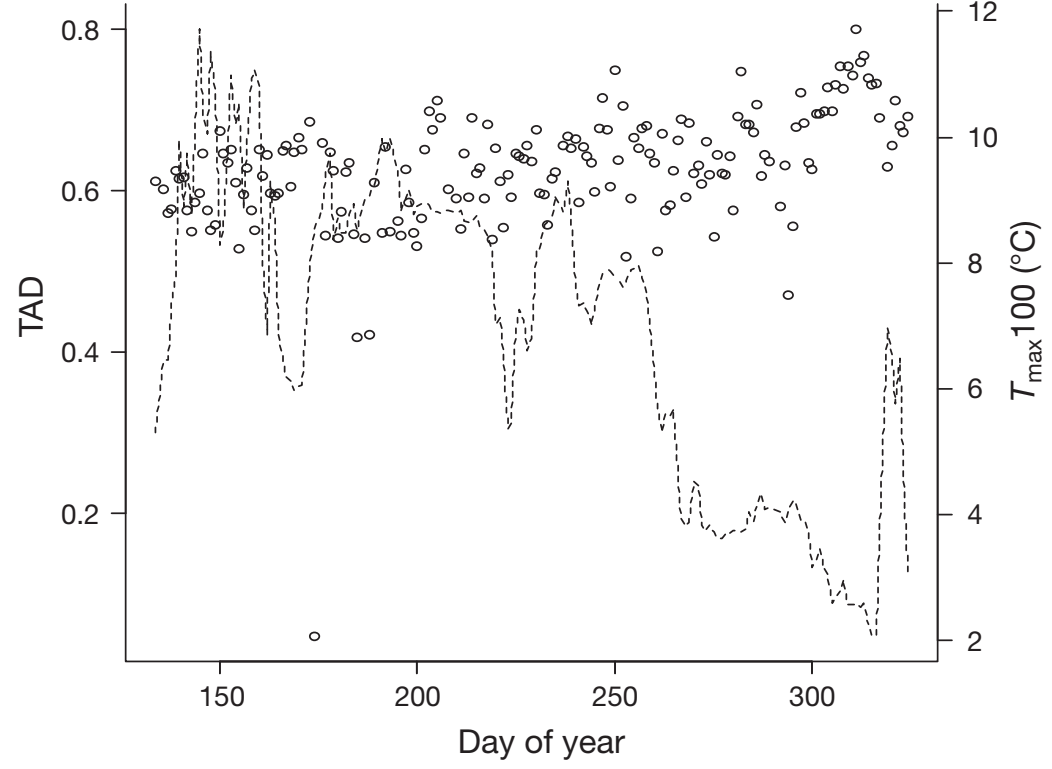

Fig. 3. Mirounga leonina. Example plot indicating the relationship between time-at-depth (TAD) (O) and $T_{\max } 100(---)$ recorded for individual 00405 (subadult male) 
cient $=-0.003)$. Scatterplots indicating the relationships between TAD and $T_{\max } 100$ (outside of the mixed model framework) are presented in Fig. 4 to highlight the size of this effect. Male TAD values were further influenced by migration stage, where TAD values tended to be higher during $\mathrm{PB}$ migrations $(0.74 \pm 0.08)$, when compared to PM migrations $(0.63 \pm 0.1)$. Female TAD values were also influenced by DVS and tended to be slightly higher when animals displayed a positive DVS $(0.68 \pm 0.1)$ when compared to neutral $(0.66 \pm 0.11)$ and negative strategies $(0.66 \pm 0.12)$. Male TAD values were also influenced by DVS, though TAD values were similar among DVS strategies (positive DVS: $0.64 \pm 0.1$; neutral DVS: $0.64 \pm 0.12$; negative DVS: $0.65 \pm 0.09$ ).

The random effects (track) explained less than $0.01 \%$ of the variance in female TAD values, and $20.7 \%$ of the variance in male dive TAD values (Table 3).

\section{Ratio of U- and W-shaped dives}

The distributions of data relating to the ratio of U- and W-shaped dives were non-normal (also after various transformations) and did not allow for the modelling of this variable in relation to other parameters. However, plots of this ratio in relation to the TAD values of $\mathrm{U}$ - and $\mathrm{W}$-shaped dives did not indi-

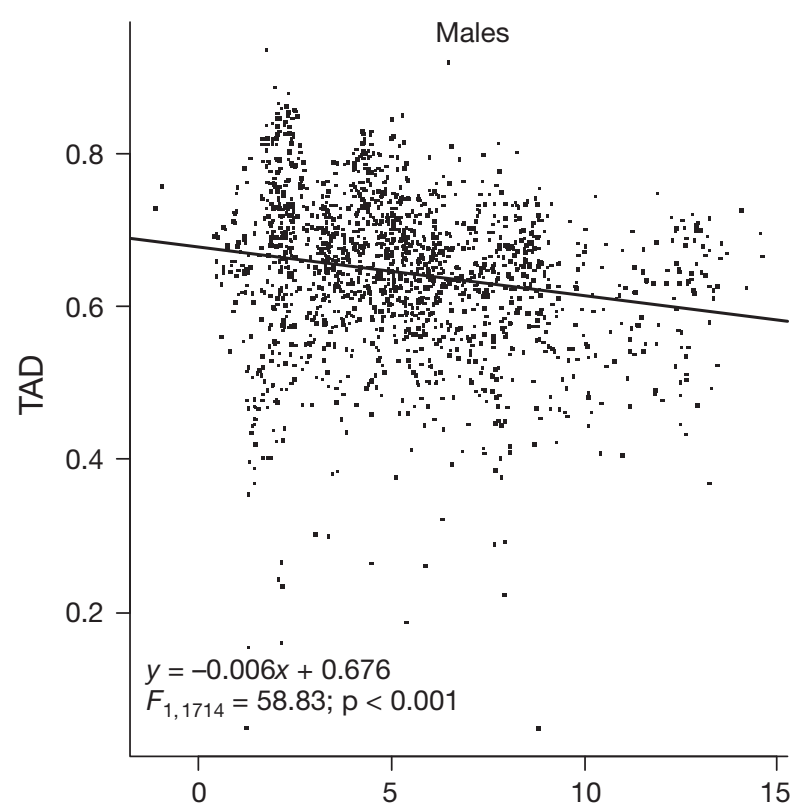

cate any clear relationship between these parameters (Fig. 5). Most of the dives were classified as either U- or W-shaped (daytime: $95 \%$; night-time: $94.3 \%$ ) (Table 2) and no increases in occurrence of these dive types were evidently associated with specific TAD values.

\section{DISCUSSION}

The diving behaviour of southern elephant seals from Marion Island is influenced by factors such as migration stage, track day, bathymetry, DVS and TAD. Variation in the dive behaviour of animals also exists between individuals and this plays an important role in explaining the models.

\section{Influence of $T_{\max } 100$}

Our results clearly illustrate a link between water temperatures at depths greater than $100 \mathrm{~m}$ and the dive behaviour of Marion Island southern elephant seals. Best models indicated that $T_{\max } 100$ significantly influenced dive depths, dive durations (except male, night-time dive durations), as well as the relative portions of time animals spent at the targeted depths of dives (TAD). This relationship was stronger for female seals, compared to males (Table 3), sug-

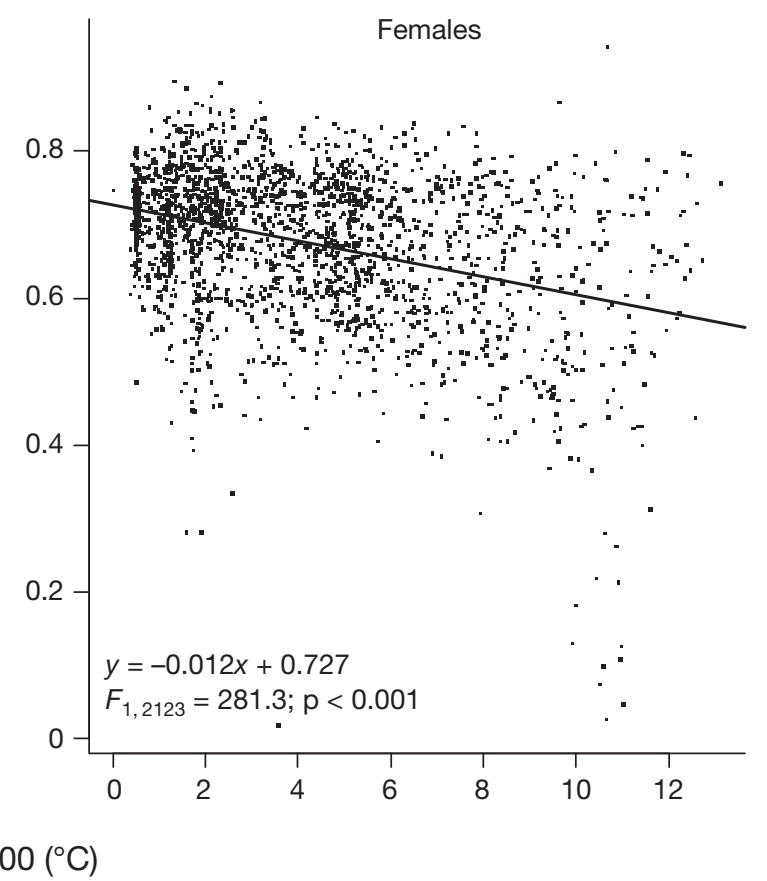

Fig. 4. Mirounga leonina. Scatterplots indicating the relationship between time-at-depth (TAD) and $T_{\max } 100$ for both sexes outside of the mixed model framework. Linear regression lines were fitted to each plot 

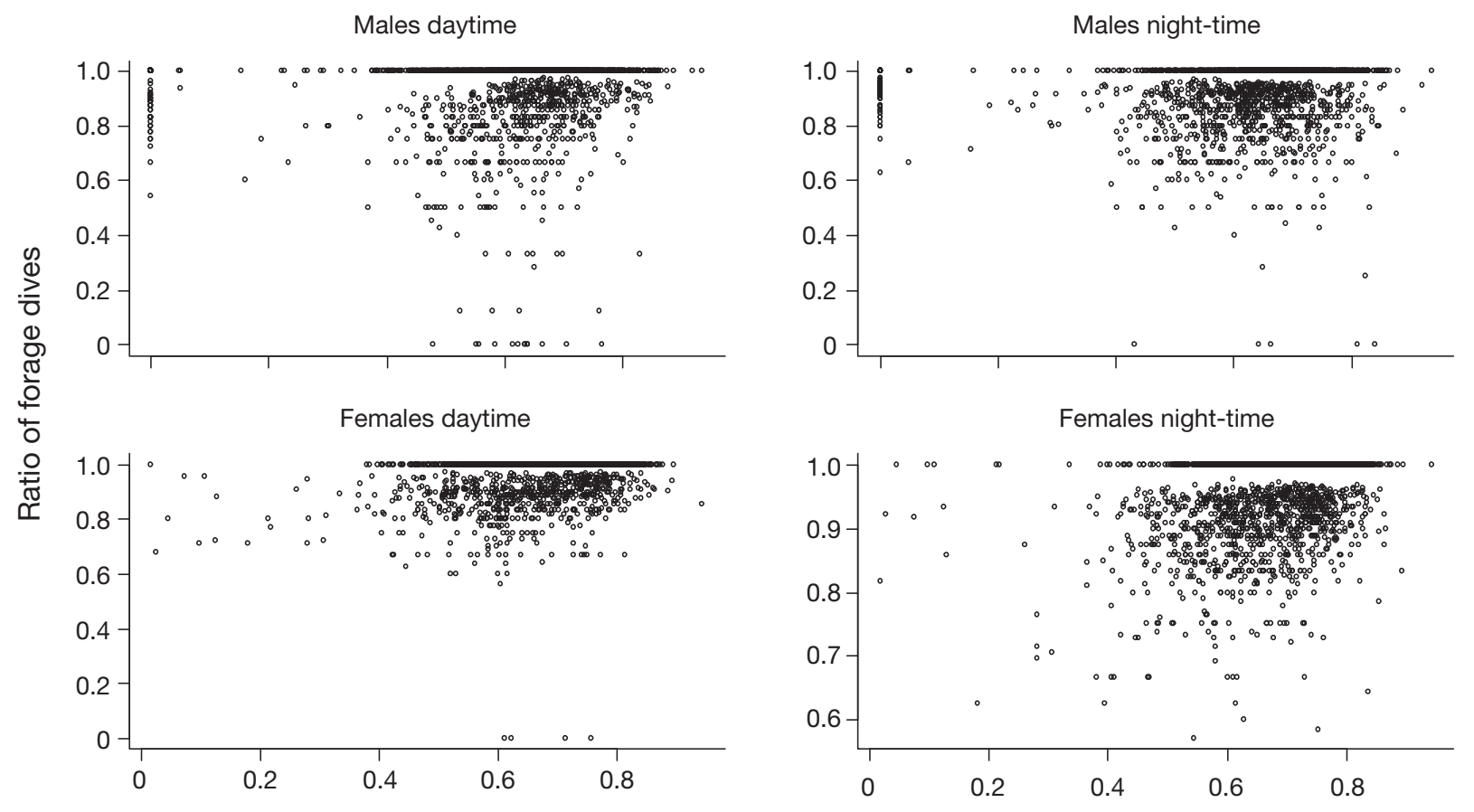

TAD

Fig. 5. Mirounga leonina. Scatterplots of mean daily time-at-depth (TAD) values and the ratio of U- and W-shaped dives recorded in our sample

gesting that increases in water temperature result in females increasing their dive depths proportionally more than males. The positive relationship of daytime dive durations with $T_{\max } 100$ was expected, given that deeper dives are mostly associated with increases in dive duration (Bennett et al. 2001). However, a less clear relationship existed between nighttime dive durations exhibited by females and $T_{\max } 100$, where animals appeared to dive for slightly shorter periods of time when $T_{\max } 100$ increased (though still to deeper depths). Further investigation into the potential role of displaying negative DVS may clarify this. Dive durations in southern elephant seal females tend to be positively related to body size (Hindell et al. 2000, Irvine et al. 2000, Hassrick et al. 2010). Unfortunately, body size or condition data were unavailable for many of the seals in our sample and we were, therefore, unable to quantify the influence of differences in body size on their dive behaviour.

The depth at which $T_{\max } 100$ values were recorded ( $T_{\max } 100$. depth) was less often related to dive parameters in our study. Night-time dive depths did exhibit a significant positive relationship with $T_{\max }$ 100.depth, indicating that seals tended to dive deeper when the $T_{\max } 100$ water layer occurred at increased depths. The influence of $T_{\max } 100$.depth on dive depths was substantially less in all cases than the $T_{\max } 100$ values themselves. While the Southern Ocean is characterised by thermal stratification in near surface waters, particularly in the Subantarctic (Pollard et al. 2002), comparatively weaker differences are observed at depth (Anilkumar et al. 2006). This may explain the general lack of influence of $T_{\max }$ 100.depth in our models. It further suggests that Marion Island elephant seals appear not to target vertical discontinuities in the thermal properties of water masses, as observed for one seal from South Georgia (Boyd \& Arnbom 1991). Similar results to the present study have been reported for northern elephant seals Mirounga angustirostris (Hakoyama et al. 1994).

Increased water temperatures at depth also influence dive type. Both male and female seals undertook dives with more equal distributions of time spent at the various depths encountered in areas with increased water temperature (dives approaching V-shapes) (see Figs. 3 \& 4). Since night-time dives tended to be deeper, but shorter in areas with warmer water, animals were able to spend more time at targeted dive depths in colder waters, resulting in dives tending to TAD values closer to 1 in areas with cooler water. We restricted the TAD models to dives that were identified as being $\mathrm{U}$ - or $\mathrm{W}$-shaped dives, 
and likely to have a foraging purpose. Within this category of dives, the seals in our sample spent proportionally less time at depth in areas with increased water temperature, when compared to colder areas. We did not assess foraging success in this investigation, though a number of proxies for foraging success have been proposed (see for example Robinson et al. 2010 and the references therein). However, the reduction in time spent at depth when animals were encountering warmer water masses suggests a smaller likelihood of successful foraging in such environments.

It is possible that elephant seals may compensate for being less able to spend time at targeted depths (while performing forage-type dives) by either increasing the absolute number of dives undertaken or by increasing the ratio of forage-type dives in relation to other dive types. Since satellite-uplink rates were variable throughout migrations, we did not have information available regarding the absolute number of dives performed by individuals during specific portions of tracks. The nature of the data relating to the relative proportions of various dive types exhibited further did not allow for the modelling of dive-type ratios in relation to TAD of foragetype dives. However, plots of this data in relation to TAD seem to indicate no pattern of compensating for less time at targeted depths by increases in foragetype dives. Our analyses could not exclude such a strategy within a statistical framework and more investigations using archival data recorders may clarify this further.

The effect of temperature on elephant seal dive behaviour is likely due to the influence of temperature on the distribution of prey species. The Southern Ocean is warming (Gille 2002), and climate models predict that this warming is likely to continue (Solomon et al. 2009, Trathan \& Agnew 2010). However, an acute limitation on studies of the Southern Ocean is its severe inaccessibility, especially during austral winter, resulting in the reliance on long-term climatic model data, rather than shipboard observations. The design of ARGO was to provide greatly improved spatial and temporal sampling in remote and harsh regions where observations have been severely hampered. Recently, using combined ARGO and XBT data, an increase in the upper layer (top $700 \mathrm{~m}$ ) heat anomaly of $0.64 \mathrm{~W} \mathrm{~m}^{-2}$ over the past $16 \mathrm{yr}$ was demonstrated (Lyman et al. 2010). At the PEI, this warming trend is certainly evident in daily sea surface temperature readings, which increased by $1.4^{\circ} \mathrm{C}$ over a 50 yr period (Mélice et al. 2003). Furthermore, ARGO data for the period 2004 to 2010 also indicated an increase of $0.15^{\circ} \mathrm{C}$ in the Subantarctic zone in the top $600 \mathrm{~m}$ (Fig. 6). Although this record is only for the past $8 \mathrm{yr}$, it does compare well to model data, which shows a significant southward shift in the subsurface expression $(\mathrm{z}=400 \mathrm{~m})$ of the SAF (E. L. Allen et al.

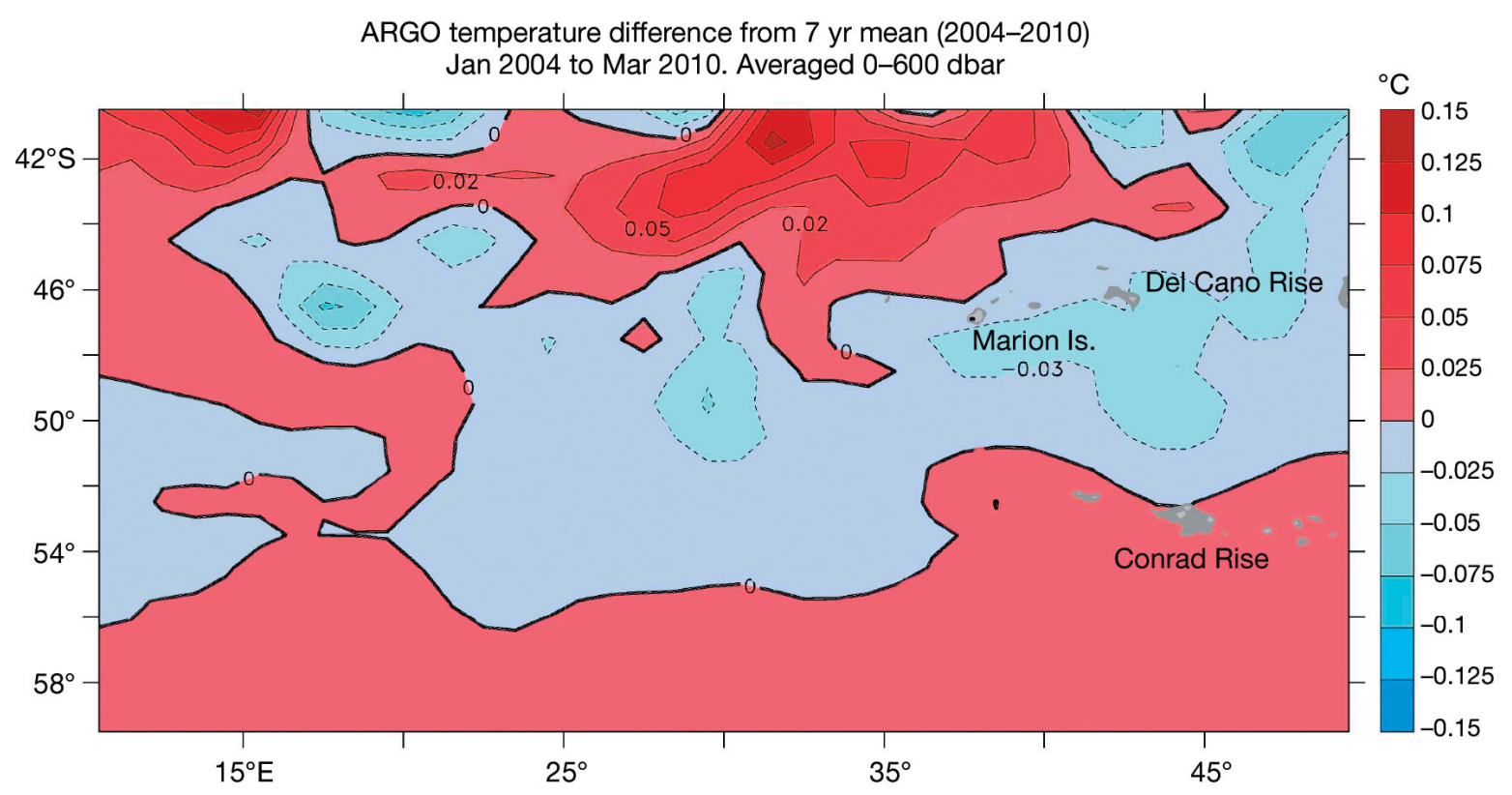

Fig. 6. ARGO profiling data highlighting the difference in temperature from the mean for the period 2004 to 2010 for the upper $600 \mathrm{~m}$. Warming trends correlate with the northern and southern boundaries of the ACC, and in particular north of the Prince Edward Islands along and north of the SAF 
unpubl.). A recent investigation into the multidecadal warming of water masses exported north of the ACC, namely Antarctic Intermediate Water (AAIW) (Schmidtko \& Johnson in press) has shown that the strongest warming trend in the upper $1000 \mathrm{~m}$ is found directly north of the SAF (Gille 2002), and compares well with the warming trend observed in Fig. 6.

One impact of this warming has been a change within the species composition of the zooplankton. A recent review (Pakhomov \& Chown 2003) of their composition around the PEI suggests that the contribution of Antarctic species has decreased by approximately $20 \%$ since the 1980 s. In contrast, subtropical species (indicative of warmer water masses) have increased from $6 \%$ to $26 \%$. This finding is further supported by incidental catches of subtropical fish species in the Polar Front Zone (PFZ) during longline fishing. Thus, it is clear that warming will lead to changes in the distribution of fish stocks, and a likely general poleward shift in fish distributions, accompanied by fish occurring at deeper depths (Perry et al. 2005, Dulvy et al. 2008, Nye et al. 2009). While the diet of southern elephant seals at Marion Island is poorly known, results from other investigations indicate that southern elephant seals largely predate on myctophid fish and squid (Slip 1995, Lewis et al. 2006, Cherel et al. 2008, Bailleul et al. 2010a). An increase in temperature in the top $1000 \mathrm{~m}$ will certainly influence the foraging behaviour of the Prince Edward Island's top predators, which could respond by either shifting their foraging grounds polewards or adapting their dive behaviour. Since southern elephant seals exhibit plasticity in forage strategies, it has been suggested that they may be able to adapt relatively easily to environmental changes (Biuw et al. 2010). However, the southern elephant seals of Marion Island represent one of the most northern breeding colonies of this species and are, together with animals from neighbouring Prince Edward Island, comparatively isolated (closest landfall being Crozet islands $\sim 1000 \mathrm{~km}$ east). While they are wideranging animals, sometimes travelling as far south as the Antarctic continental shelf, this behaviour is not common and most animals forage primarily pelagically in inter-frontal zones (this study, Jonker \& Bester 1998, Tosh 2010, McIntyre et al. 2011). The location of their terrestrial breeding habitat potentially limits their ability to undertake range shifts, thus necessitating the seals to adapt their dive behaviour. Elephant seals from Marion Island are known to be extreme divers, generally diving deeper than has been recorded for other populations (Mc-
Intyre et al. 2011). Shifts in the vertical distribution of prey species due to changes in water temperature may therefore lead to seals having to dive even deeper (requiring longer dive durations), resulting in greater physiological costs associated with diving. This effect may be greater in female southern elephant seals than males. While we did not record behaviour from juvenile animals in our sample, it is expected that such influences may be even greater on juveniles due to their reduced diving capabilities (Field et al. 2005).

\section{Influence of DVS}

The seals in our sample exhibited a range of diel diving strategies, ranging from positive (deeper dive depths during the day, when compared to night-time dives) to negative (deeper dive depths during the night, when compared to daytime dives) strategies. While the positive DVS is common amongst elephant seals that forage in pelagic environments (Hindell 1991, Jonker \& Bester 1994), the negative strategy is less common and has only recently been described for seals from Marion Island (Jonker 1997, McIntyre et al. 2011). DVS predictably influenced both the depth and durations of dives made by seals in our sample. Seals further tended to spend more time at depth (with calculated TAD values closer to 1) when exhibiting a positive DVS. The differences in TAD values obtained for elephant seals exhibiting different diel strategies indicate that elephant seals are able to spend more time at targeted depths, when exhibiting positive strategies, compared to neutral or negative strategies. Since little dietary information is available for this population of southern elephant seals, interpreting the differences in DVS is difficult. Undertaking dives with lower TAD values that approach 0.5 (i.e. displaying a time-depth profile that approaches a V-shape) is normally considered to represent exploration-type dives that likely carry substantial physiological costs (given that little to no foraging takes place). Explaining why an increase of such dive behaviour is associated with the neutral or negative DVS will require more information related to prey species taken (and quantity) whilst displaying such different strategies.

\section{Influence of migration stage}

Differences in dive behaviour between migration stages were evident in night-time dive durations and 
TAD values attained by male southern elephant seals. Males made longer night-time dives during PM trips when compared to PB trips. Males tracked on PB migrations were older than males tracked on PM migrations $\left(\mathrm{PB}=9.4 \pm 1.6 \mathrm{yr}_{;} \mathrm{PM}=5.4 \pm 2.5 \mathrm{yr}\right)$, suggesting that males on $\mathrm{PB}$ migrations in our sample were likely to be larger than males tracked on PM migrations. Since PM males dived for longer than PB males, irrespective of body size, the shallower dives observed during PB migrations may be due to a loss of body condition and fitness resulting from participating in the breeding haulout (Carlini et al. 2004, Galimberti et al. 2007). Furthermore, dive durations increase as migrations progress (Bennett et al. 2001), and since the PB migrations are shorter than the PM migrations, animals have less time available to them in the PB migrations to improve their fitness enough to sustain longer dive durations. An alternative explanation may be that food resources are more readily available in the austral summer, not requiring such long dives. Also, variations in day length between migration stages are likely to influence the diel patterns of vertically migrating prey, influencing the observed dive behaviours. We did not account for variations in day length here. Adult male seals also spent more time at depth during PB migrations (higher TAD values), compared to PM migrations. Shallower dives during PB migrations may allow the seals greater amounts of time at targeted depths, accessing readily available food resources and thereby resulting in more dives with TAD values closer to 1 .

Female elephant seals in our sample also exhibited differences in dive duration between migrations, though the influence of migration stage was not identified as a significant influence in the most parsimonious model. Dive durations are known to be influenced by body size and condition (Irvine et al. 2000, Hassrick et al. 2010). It is therefore likely that the differences observed in dive durations are due to differences in condition upon departing for PM versus $\mathrm{PB}$ migrations. Our results could not, however, exclude the possibility of differences in forage strategy and/or diet, or the influence of day length variation, between the migration stages affecting the dive durations of Marion Island elephant seals.

\section{Influence of track day}

Track day had a significant influence on various dive parameters modelled here, including all models for dive durations, and dive depths of female southern elephant seals. Dive durations tend to increase as a function of time during migrations, and could be as a result of increases in muscle oxygen storage ability and fitness (Bennett et al. 2001). Track day influences on the dive depths of female southern elephant seals may be related to the influences of track day on dive durations of this group. This may indicate that dive depths are further constrained by physiological ability of female elephant seals.

\section{CONCLUSION}

Elephant seals routinely dive beyond their calculated aerobic dive limits (Butler 2006) and are capable of tolerating extreme hypoxemia (Meir et al. 2009). Our results suggest that southern elephant seals from Marion Island tend to dive deeper and spend less time at targeted depths in warmer water bodies. This is likely the result of vertical shifts in the distribution of preferred prey in relation to water temperature. Under current climate predictions, the world's oceans will continue warming and prey distributional shifts due to ocean warming will likely lead to the Marion Island elephant seals having to either shift their migration ranges poleward, or target deeper water layers. Shifts in migration ranges (particularly the shorter PB migrations) may be constrained by the comparatively low latitude of the PEI, necessitating deeper diving strategies. Since the Marion Island elephant seals are possibly diving close to their physiological limits under current conditions, such deeper diving may lead to greater longterm physiological costs and decreased survivorship in this population. Investigations to determine the preferred prey species of southern elephant seals (and their respective habitat preferences and thermal tolerances) are required to better quantify the potential impacts of climate changes on the foraging behaviour of this marine predator.

Acknowledgements. G. Hofmeyr, B. Stewart, P. Radzilani, N. de Bruyn, C. Oosthuizen, M. Phalanndwa, R. Reisinger and T. Mufanadzo are gratefully acknowledged for their assistance with the deployments of satellite tags. M. Biuw generously provided R codes (and helpful assistance) for the dive classifications and the use of the maptools package. The Alfred Wegener Institute for Polar and Marine Research (Germany), the Department of Science and Technology through the National Research Foundation (South Africa) and the South African National Antarctic Programme provided financial and logistical support. Much of this research was carried out under the South Africa / Germany part of the project MEOP (Marine Mammals Exploring the Oceans Pole to Pole), carried out as part of the International Polar Year. We also thank 2 anonymous reviewers for their valuable comments that greatly improved this manuscript. 


\section{LITERATURE CITED}

Anilkumar N, Alvarinho JL, Somayajulu B, Ramesh Babu V and others (2006) Fronts, water masses and heat content variability in the Western Indian sector of the Southern Ocean during austral summer 2004. J Mar Syst 63:20-34

Ansorge IJ, Durgadoo JV, Pakhomov EA (2009) Dynamics of physical and biological systems of the Prince Edward Islands in a changing climate. Pap Proc R Soc Tasman 143:15-18

Argos (1996) Argos user's manual. Collecte Localisation Satellites (CLS)

Bailleul F, Charrassin JB, Monestiez P, Roquet F, Biuw M, Guinet C (2007) Successful foraging zones of southern elephant seals from the Kerguelen Islands in relation to oceanographic conditions. Philos Trans R Soc Lond B Biol Sci 362:2169-2181

Bailleul F, Authier M, Ducatez S, Roquet F, Charrassin JB, Cherel Y, Guinet C (2010a) Looking at the unseen: combining animal bio-logging and stable isotopes to reveal a shift in the ecological niche of a deep diving predator. Ecography 33:709-719

Bailleul F, Cotté C, Guinet C (2010b) Mesoscale eddies as foraging area of a deep-diving predator, the southern elephant seal. Mar Ecol Prog Ser 408:251-264

Belkin IM, Gordon AL (1996) Southern Ocean fronts from the Greenwich meridian to Tasmania. J Geophys Res 101:3675-3696

Bennett KA, McConnell BJ, Fedak M (2001) Diurnal and seasonal variations in the duration and depth of the longest dives in southern elephant seals (Mirounga leonina): possible physiological and behavioural constraints. J Exp Biol 204:649-662

Bester MN (1988) Chemical restraint of Antarctic fur seals and southern elephant seals. S Afr J Wildl Res 18: $57-60$

Biuw M, Boehme L, Guinet C, Hindell MA and others (2007) Variations in behavior and condition of a Southern Ocean top predator in relation to in situ oceanographic conditions. Proc Natl Acad Sci USA 104:13705-13710

Biuw M, Nøst OA, Stien A, Zhou Q, Lydersen C, Kovacs KM (2010) Effects of hydrographic variability on the spatial, seasonal and diel diving patterns of southern elephant seals in the eastern Weddell Sea. PLoS ONE 5:e13816

> Boehme L, Lovell P, Biuw M, Roquet F and others (2009) Technical note: Animal-borne CTD-Satellite Relay Data Loggers for real-time oceanographic data collection. Ocean Sci 5:685-695

Bolker BM (2008) Ecological models and data in R. Princeton University Press, NJ

Bolker BM, Brooks ME, Clark CJ, Geange SW, Poulsen JR, Stevens HH, White JSS (2009) Generalized linear mixed models: a practical guide for ecology and evolution. Trends Ecol Evol 24:127-135

> Bornemann H, Kreyscher M, Ramdohr S, Martin T, Carlini AR, Sellmann L, Plötz J (2000) Southern elephant seal movements and Antarctic sea ice. Antarct Sci 12:3-15

Boyd IL, Arnbom T (1991) Diving behaviour in relation to water temperature in the southern elephant seal: foraging implications. Polar Biol 11:259-266

Breiman L (2001) Random forests. Mach Learn 45:5-32

Bunnefeld N, Newborn D, Milner-Gulland EJ (2009) Factors affecting unintentional harvesting selectivity in a monomorphic species. J Anim Ecol 78:485-492
Burnham KP, Anderson DR (2002) Model selection and multimodel inference: a practical information-theoretic approach. Springer Science + Business Media, New York

- Butler PJ (2006) Aerobic dive limit. What is it and is it always used appropriately? Comp Biochem Physiol A Mol Integr Physiol 145:1-6

Carlini AR, Marquez MEI, Panarello HO, Ramdohr S, Daneri GA, Bornemann H, Plötz J (2004) Lactation costs in southern elephant seals at King George Island, South Shetland Islands. Polar Biol 27:266-276

Cherel Y, Ducatez S, Fontaine C, Richard P, Guinet C (2008) Stable isotopes reveal the trophic position and mesopelagic fish diet of female southern elephant seals breeding on the Kerguelen Islands. Mar Ecol Prog Ser 370: 239-247

Crawley MJ (2007) The R book. John Wiley \& Sons, Chichester

Dragon AC, Monestiez P, Bar-Hen A, Guinet C (2010) Linking foraging behaviour to physical oceanographic structures: Southern elephant seals and mesoscale eddies east of Kerguelen Islands. Prog Oceanogr 87:61-71

> Dulvy NK, Rogers SI, Jennings S, Stelzenmüller V, Dye SR, Skjoldal HR (2008) Climate change and deepening of the North Sea fish assemblage: a biotic indicator of warming seas. J Appl Ecol 45:1029-1039

> Fedak M, Lovell P, Grant SM (2001) Two approaches to compressing and interpreting time-depth information as collected by time-depth recorders and satellite-linked data recorders. Mar Mamm Sci 17:94-110

Ferguson SH, Stirling I, McLoughlin P (2005) Climate change and ringed seals (Phoca hispida) recruitment in western Hudson Bay. Mar Mamm Sci 21:121-135

Field I, Hindell MA, Slip D, Michael KJ (2001) Foraging strategies of southern elephant seals (Mirounga leonina) in relation to frontal zones and water masses. Antarct Sci 13:371-379

Field IC, Bradshaw CJA, Burton HR, Sumner MD, Hindell MA (2005) Resource partitioning through oceanic segregation of foraging juvenile southern elephant seals (Mirounga leonina). Oecologia 142:127-135

Galimberti F, Sanvito S, Braschi C, Boitani L (2007) The cost of success: reproductive effort in male southern elephant seals (Mirounga leonina). Behav Ecol Sociobiol 62:159-171

Gille ST (2002) Warming of the Southern Ocean since the 1950s. Science 295:1275-1277

> Hakoyama H, Le Boeuf BJ, Naito Y, Sakamoto W (1994) Diving behavior in relation to ambient water temperature in northern elephant seals. Can J Zool 72:643-651

> Harcourt RG, Bradshaw CJA, Dickson K, Davis LS (2002) Foraging ecology of a generalist predator, the female New Zealand fur seal. Mar Ecol Prog Ser 227:11-24

Hassrick JL, Crocker DE, Teutschel NM, McDonald BI, Robinsons PW, Simmons SE, Costa DP (2010) Condition and mass impact oxygen stores and dive duration in adult female northern elephant seals. J Exp Biol 213: 585-592

Hindell MA (1991) Some life-history parameters of a declining population of southern elephant seals, Mirounga leonina. J Anim Ecol 60:119-134

> Hindell MA, Slip DJ, Burton HR (1991) The diving behaviour of adult male and female southern elephant seals, Mirounga leonina (Pinnipedia: Phocidae). Aust J Zool 39: 595-619 
Hindell MA, Lea MA, Morrice MG, McMahon CR (2000) Metabolic limits on dive duration and swimming speed in the southern elephant seal Mirounga leonina. Physiol Biochem Zool 73:790-798

IOC, IHO, BODC (2003) Centenary edition of the GEBCO digital atlas. Published on CD-ROM on behalf of the Intergovernmental Oceanographic Commission and the International Hydrographic Organization as part of the General Bathymetric Chart of the Oceans. British Oceanographic Data Centre, Liverpool

Irvine LG, Hindell MA, van den Hoff J, Burton HR (2000) The influence of body size on dive duration of underyearling southern elephant seals (Mirounga leonina). J Zool (Lond) 251:463-471

Jonker FC (1997) Ranging and diving behaviour of adult female southern elephant seals from Marion Island. MSc dissertation, University of Pretoria

Jonker FC, Bester MN (1994) The diving behaviour of adult southern elephant seal, Mirounga leonina, cows from Marion Island. S Afr J Antarct Res 24:75-93

Jonker FC, Bester MN (1998) Seasonal movements and foraging areas of adult southern female elephant seals, Mirounga leonina, from Marion Island. Antarct Sci 10: 21-30

Large WG, Yeager SG (2004) Diurnal to decadal global forcing for ocean and sea-ice models: the data sets and flux climatologies. National Center for Atmospheric Research (NCAR) Technical Note NCAR/TN-460+STR

Le Boeuf BJ, Laws RM (1994) Elephant seals: population ecology, behavior, and physiology. University of California Press, Berkeley

Le Roux PC, McGeoch M (2008) Rapid range expansion and community reorganization in response to warming. Glob Change Biol 14:2950-2962

Learmonth JA, MacLeod CD, Santos MB, Pierce GJ, Crick HQP, Robinson RA (2006) Potential effects of climate change on marine mammals. Oceanogr Mar Biol Annu Rev 44:431-464

Levitus S, Antonov JI, Boyer TP, Stephens C (2000) Warming of the world ocean. Science 287:2225-2229

Lewin-Koh NJ, Bivand R (2008) maptools: Tools for reading and handling spatial objects. $\mathrm{R}$ package version 0.7-16

Lewis R, O'Connell T, Lewis M, Campagna C, Hoelzel AR (2006) Sex-specific foraging strategies and resource partitioning in the southern elephant seal (Mirounga leonina). Proc R Soc B 273:2901-2907

Liaw A, Wiener M (2002) Classification and regression by randomForest. R News 2:18-22

Lyman JM, Good SA, Gouretski W, Ishii M and others (2010) Robust warming of the global upper ocean. Nature 465: 334-337

- McIntyre T, de Bruyn PJN, Ansorge IJ, Bester MN, Bornemann H, Plötz J, Tosh CA (2010a) A lifetime at depth: vertical distribution of southern elephant seals in the water column. Polar Biol 33:1037-1048

> McIntyre T, Tosh CA, Plötz J, Bornemann H, Bester MN (2010b) Segregation in a sexually dimorphic mammal: a mixed-effects modelling analysis of diving behaviour in southern elephant seals. Mar Ecol Prog Ser 412:293-304

McIntyre T, Bornemann H, Plötz J, Tosh CA, Bester MN (2011) Water column use and forage strategies of female southern elephant seals from Marion Island. Mar Biol 158:2125-2139

McMahon CR, Burton HR (2005) Climate change and seal survival: evidence for environmentally mediated changes in elephant seal, Mirounga leonina, pup survival. Proc Biol Sci 272:923-928

- Meir JU, Champagne CD, Costa DP, Williams CL, Ponganis PJ (2009) Extreme hypoxemic tolerance and blood oxygen depletion in diving elephant seals. Am J Physiol Regul Integr Comp Physiol 297:R927-R939

Mélice JL, Lutjeharms JRE, Rouault M, Ansorge IJ (2003) Sea-surface temperatures at the sub-Antarctic islands Marion and Gough during the past 50 years. S Afr J Sci 99:363-366

Meredith MP, Hogg AM (2006) Circumpolar response of Southern Ocean eddy activity to a change in the Southern Annular Mode. Geophys Res Lett 33:L16608

> Nye JA, Link JS, Hare JA, Overholtz WJ (2009) Changing spatial distribution of fish stocks in relation to climate and population size on the Northeast United States continental shelf. Mar Ecol Prog Ser 393:111-129

Pakhomov EA, Chown SL (2003) The Prince Edward Islands: Southern Ocean oasis. Ocean Yearbook 17:348-379

> Perry AL, Low PJ, Ellis JR, Reynolds JD (2005) Climate change and distribution shifts in marine fishes. Science 308:1912-1915

Photopoulos T (2007) Behavioural changes of a long-ranging diver in response to oceanographic conditions. MSc thesis, University of St Andrews

Pinheiro JC, Bates DM (2004) Mixed-effects models in S and S-lus. Springer, New York, NY

> Pollard RT, Lucas MI, Read JF (2002) Physical controls on biogeochemical zonation in the Southern Ocean. DeepSea Res II 49:3289-3305

R Development Core Team (2008) R: A language and environment for statistical computing. R Foundation for Statistical Computing, Vienna, 3-900051-07-0 www.Rproject.org

Robinson PW, Simmons SE, Crocker DE, Costa DP (2010) Measurements of foraging success in a highly pelagic marine predator, the northern elephant seal. J Anim Ecol 79:1146-1156

Roemmich D, Gilson J (2009) The 2004-2008 mean and annual cycle of temperature, salinity, and steric height in the global ocean from the Argo Program. Prog Oceanogr 82:81-100

Roemmich DH, Owens WB (2000) The Argo project: global ocean observations for understanding and prediction of climate variability. Oceanography 13:45-50

Roemmich D, Riser S, Davis R, Desaubies Y (2004) Autonomous profiling floats: workhorse for broad-scale ocean observations. Mar Technol Soc J 38:31-39

Schlitzer R (2002) Interactive analysis and visualization of geoscience data with Ocean Data View. Comput Geosci 28:1211-1218

Schmidtko S, Johnson GC (in press) Multi-decadal warming and shoaling of Antarctic Intermediate Water. J Clim

Simmonds MP, Isaac SJ (2007) The impacts of climate change on marine mammals: early signs of significant problems. Oryx 41:19-26

Slip DJ (1995) The diet of southern elephant seals (Mirounga leonina) from Heard Island. Can J Zool 73: 1519-1528

Solomon S, Plattner GK, Knutti C, Friedlingstein P (2009) Irreversible climate change due to carbon dioxide emissions. Proc Natl Acad Sci USA 106:1704-1709

Tosh CA (2010) Oceanographic signatures and foraging areas of southern elephant seals. PhD thesis, University of Pretoria 
Tosh CA, Bornemann H, Ramdohr S, Schröder M and others (2009) Adult male southern elephant seals from King George Island utilize the Weddell Sea. Antarct Sci 21: 113-121

$>$ Trathan PN, Agnew D (2010) Climate change and the Antarctic marine ecosystem: an essay on management implications. Antarct Sci 22:387-398

Editorial responsibility: Michael Castellini,

Fairbanks, Alaska, USA van den Hoff J, Burton HR, Hindell MA, Sumner MD, McMahon CR (2002) Migrations and foraging of juvenile southern elephant seals from Macquarie Island within CCAMLR managed areas. Antarct Sci 14: 134-145

Wilson S (2000) Launching the Argo Armada. Oceanus 42: $17-19$

Submitted: December 9, 2010; Accepted: September 2, 2011 Proofs received from author(s): October 27, 2011 